Ebisu Ebisu

Études japonaises Études japonaises

$51 \mid 2014$

Le rapprochement franco-japonais dans l'entre-deuxguerres

\title{
Matthieu SÉGUÉLA, Clemenceau ou la tentation du Japon
}

Paris, CNRS éditions, 2014, 472 p.

\section{Jean Baubérot}

\section{OpenEdition}

\section{Journals}

Édition électronique

URL : http://journals.openedition.org/ebisu/1531

DOI : $10.4000 /$ ebisu. 1531

ISSN : 2189-1893

Éditeur

Institut français de recherche sur le Japon à la Maison franco-japonaise (UMIFRE 19 MEAE-CNRS)

Référence électronique

Jean Baubérot, " Matthieu séguéta, Clemenceau ou la tentation du Japon », Ebisu [En ligne], 51 | 2014

mis en ligne le 01 novembre 2014, consulté le 22 septembre 2020. URL : http://

journals.openedition.org/ebisu/1531; DOI : https://doi.org/10.4000/ebisu.1531

Ce document a été généré automatiquement le 22 septembre 2020.

(c) Institut français de recherche sur le Japon à la Maison franco-japonaise 


\title{
Matthieu SÉGUÉLA, Clemenceau ou la tentation du Japon
}

Paris, CNRS éditions, 2014, 472 p.

\author{
Jean Baubérot
}

\section{RÉFÉRENCE}

Matthieu SÉGUÉLA, Clemenceau ou la tentation du Japon, Paris, CNRS éditions, 2014, 472 p.

L'ouvrage de Matthieu Séguéla aborde un sujet neuf que l'on pourrait croire " pointu »: l'attirance de Clemenceau envers le Japon. En fait, ce livre constitue une importante contribution à un des problèmes les plus intéressants de l'historiographie contemporaine : la mutation du rapport de l'Occident avec d'autres civilisations, ses raisons, ses conséquences aussi bien anthropologiques que géopolitiques.

Dans les premières décennies de la Troisième République, l'Extrême-Orient en général et le Japon en particulier sont victimes de théories racialistes. Ainsi, le dreyfusard et futur prix Nobel, Charles Richet, soutient que «la supériorité de la race blanche est d'une absolue évidence ». Certes, les hommes sont "frères", mais ceux de "race jaune» sont des «frères inférieurs"! Ils constituent pourtant une menace: Guillaume II incite la Russie à «défendre la civilisation chrétienne contre le péril jaune » et des économistes, comme Edmond Théry, théorisent ce « péril » comme étant «la rupture violente de l'équilibre économique», due au «brusque réveil» d'une « immense région » disposant du " tiers de la population terrestre ».

3 Face à ces idées largement dominantes, il existe chez des artistes, certains journalistes et parmi l'extrême gauche, une minorité de japonophiles. Clemenceau en fait partie, tout en constituant un cas unique. En effet, son penchant pour le Japon couvre plusieurs champs : esthétique, intellectuel, politique. Par ailleurs, le Vendéen est de loin le plus célèbre des amis du Japon, celui dont les propos ont le plus d'impact. Enfin, sa carrière va lui permettre de donner une efficacité politique relative mais non négligeable à sa passion japonaise. Après avoir lu Séguéla, la méconnaissance passée de 
la « tentation » du Tigre apparaît étrange : comment a-t-on pu négliger un aspect aussi important de sa personnalité, décisif à certains moments de ses activités de parlementaire et de chef de gouvernement?

4 Séguéla distingue trois périodes : le " Japon intérieur » de Clemenceau (1868-1894), la « décennie perdue » (1895-1905) et les « Treize Glorieuses » (1907-1919).

5 Le Japon intérieur. Lors de son séjour aux États-Unis (1865-1869), Clemenceau remarque les flux humains venus d'Extrême-Orient. Il s'agit surtout de Chinois. Mais son intérêt pour ce qu'il nomme l'« Extrême Asie » va se focaliser sur le Japon, dès les années 1870, par la rencontre, à Paris, de jeunes Japonais, partisans du libéralisme politique, tel Saionji Kinmochi dont la carrière politique aura de nombreuses correspondances avec la sienne. Grâce à ces amitiés, son journal La Justice publie des "Lettres du Japon», en 1885 et en 1890, qui valorisent la modernisation et la démocratisation de ce pays. Un ressortissant japonais collabore au journal, en 1891-1892, ce qui représente alors une forte novation. Cet intérêt politique va de pair avec un engouement esthétique. Clemenceau acquiert une très belle collection d'objets d'art japonais. Malheureusement, il doit la vendre en 1894 pour honorer ses créances. Il conserve, malgré tout, plus de 2500 kōgō, aujourd'hui encore la plus importante collection jamais rassemblée en France. Sa passion de l'art asiatique le conduit à soutenir la création du musée Guimet et à jouer un rôle quant au musée du Louvre et au musée d'Ennery : Le « tombeur de ministères » est un « faiseur de musées »!

6 Très judicieusement, Séguéla relie, chez Clemenceau, cette reconnaissance de la valeur «d'un art non occidental» avec «l'affirmation égalitaire des races et de leurs civilisations». Il montre comment, le Vendéen, quoiqu'influencé par les théories racialistes, les subvertit. La relecture opérée par notre auteur de la célèbre apostrophe de Clemenceau face à Ferry le 30 juillet 1885 est passionnante. Alors qu'il est question de Madagascar, les exemples donnés pour contester l'expression de «races inférieures » connotent tous l'Extrême-Orient. En fait, pour Clemenceau, la différence entre les races provient non de la couleur de la peau mais de leurs rapports à la «puissance émancipatrice du travail». On comprend que, dans cette optique, les Japonais ne soient nullement considérés comme «inférieurs»! Ce changement de paradigme se double d'une attirance pour le bouddhisme (qu'il partage, ajouteronsnous, avec son adversaire Ferry, lequel voyait dans l'enseignement de Bouddha l'origine de la morale laïque !).

7 La décennie perdue va de la guerre sino-japonaise de 1895 à la guerre russo-japonaise de 1904-1905. Estimant, comme beaucoup d'autres, la conquête de la Chine inéluctable, pour sa modernisation, Clemenceau juge le Japon moins illégitime que les Européens pour devenir l'éducateur de l'Empire chinois. Il salue les progrès du libéralisme politique dans le pays du Soleil Levant, est impressionné par la hausse spectaculaire de sa production industrielle, mais se montre conscient de son coût humain : «la vaste usine mangeuse d'hommes, de femmes, d'enfants qui, silencieusement tue d'accidents ou de misère, plus d'êtres humains que la guerre intermittente à ciel ouvert ».

$8 \mathrm{Au}$ moment de la guerre russo-japonaise, le sénateur Clemenceau est une figure de la majorité gouvernementale, or la Russie est l'alliée de la France. Lucidement, il met en garde ceux qui croient à une facile victoire russe et s'il « donne tort au Japon » d'avoir déclenché le conflit sans déclaration de guerre, c'est l'unique critique qu'il adresse à ce pays. Quand le directeur du Temps le classe parmi les «irresponsables d'extrême gauche ", il rappelle son attachement à l'alliance franco-russe. En même temps, il 
oppose le despotisme tsariste et les avancées démocratiques japonaises et relève que les " officiers du mikado " apprennent à lire et à écrire le russe aux soldats illettrés qu'ils ont fait prisonniers. La rédaction de L'Aurore est majoritairement favorable au Japon, même si cet appui n'est pas unanime. Picquart salue la «victoire du maître d'école japonais sur le pope russe ». D'autres militants laïques, tel Gustave Hervé, partagent alors cette position.

Clemenceau prend la mesure de l'événement qu'il juge «capital dans l'histoire des rencontres de l'Europe et de l'Asie. L'homme blanc se voit arrêté par l'homme jaune dans son mouvement de conquête sans fin ». Il ne se prive pas de critiquer, à plusieurs reprises, la diplomatie française, officiellement neutre mais qui ravitaille la flotte russe dans ses colonies. Après le traité de paix, il salue «l'apparition d'une grande puissance asiatique (...) fait nouveau dans l'histoire humaine. » Il n'est pas le seul à effectuer ce diagnostic, mais il va pouvoir en tenir compte puisqu'il accède au pouvoir en octobre 1906.

10 Commence alors la dernière période que Séguéla intitule les "Treize Glorieuses " (1907-1919). Clemenceau est, à deux reprises, président du Conseil (oct. 1906-juil. 1909; nov. 1917-janv. 1920). Avec son ministre des Affaires étrangères, Stephen Pichon (également ministre de 1909 à 1911), il tente d'appliquer ses idées. En 1907, cette entreprise est facilitée par le fait que son vieil ami Saionji dirige le gouvernement japonais. Son arrivée au pouvoir accélère donc un processus de recadrage de la diplomatie française, déjà entamé antérieurement. Un « arrangement » franco-japonais garantit les possessions des deux puissances en Asie. Il permet indirectement l'émergence d'une "quadruple entente », conciliant les intérêts de la France, du Japon, du Royaume-Uni et de la Russie. Le Japon peut emprunter, sur le marché français, des capitaux lui permettant de rembourser ses dettes, dues à la guerre de 1904-1905.

11 En 1917-1918, c'est au tour du Japon d'autoriser la France à emprunter sur le marché de Tokyo. Dès le début de la Grande Guerre, Clemenceau anime une campagne de presse pour convaincre du bien-fondé d'une intervention militaire japonaise en Europe. Séguéla montre bien l'aspect utopique de cette «vision géopolitique originale » : elle dispose d'un certain appui de la diplomatie française mais échoue à cause des réticences britanniques, des hésitations russes et surtout du refus du Japon de s'engager ainsi. Clemenceau persiste pourtant dans son projet, même s'il admet les nombreuses difficultés qu'entrainerait sa réalisation (logistique, langue, nourriture...). Revenu au pouvoir, il obtient, au début de 1918, une intervention armée japonaise en Sibérie et un bataillon français se bat sous commandement nippon.

12 Séguéla termine son magistral ouvrage par l'action de Clemenceau à la Conférence de Versailles. La France appuie la proposition japonaise d'opposition à toute législation inégalitaire "sous prétexte de race ou de nationalité ", mais se heurte à l'opposition des Anglo-Saxons. Le représentant japonais proteste alors avec vigueur. En revanche, s'estimant lié par des accords signés au début de 1917, Clemenceau, bien qu'en retrait, accepte que le Japon hérite des droits de l'Allemagne dans le Shandong, ce qui conduira la Chine à ne pas signer le traité de Paix. Il estime «d'importance capitale » pour la France de " conserver une bonne amitié japonaise ».

13 Ainsi, malgré quelques désenchantements, Clemenceau est, dans la longue durée, un ami du Japon. Il n'y est pourtant jamais allé mais a pu dire que « les plus beaux voyages sont ceux que l'on ne fait pas ». Matthieu Séguéla, analysant l'inclination japonaise du Tigre, nous livre une très belle contribution à l'historique des relations franco- 
nippones et, au-delà, nous donne des éléments précieux pour une réflexion sur l'histoire contemporaine. Son ouvrage concilie l'érudition et la hauteur de vue. Retenons, pour finir, sa citation d'un propos de Clemenceau, en 1921, à un visiteur Japonais. Elle montre que l'amitié n'empêche pas la lucidité :

«Le Japon aura des problèmes graves en Corée (... comme) la France avec l'Afrique $\mathrm{du}$ Nord (... car) c'est amoral de conquérir les peuples et les nations. (Et) il est difficile de les gouverner.»

\section{AUTEURS}

JEAN BAUBÉROT

EPHE 